\title{
FROM DEBATE TO DIALOGUE: Toward a Pedagogy of Nonpolarized Public Discourse
}

\section{Bruce Hyde and Jeffery L. Bineham}

This essay describes the rationale, content, and structure of a team-taught course which explored the difference between debate and dialogue asforms ofpublic discourse. Our thesis is that the value of public argument in our culture is undermined by its tendency to polarize popular opinion, and that this situation could be improved by the development $g$ a pedagogy of dialogue to balance our discipline's traditional emphasis on debate. The essay is divided intofour sections. Thefirst section examines our discipline's view of argument. The second section explores the question of dialogue's "teachability," and the third section proposes severalfundamental components of a pedagogy of dialogue. The final section describes the format of the team-taught course that the authors designed to explore the comparative benefits of debate and dialogue asformsforpublic discourse.

$\mathbf{T}$ he limitations imposed upon public deliberation by our culture's predisposition to address issues through polarized discourse-i.e., debate-were never so clear as in the televised hearings of the Judiciary Committee of the United States House of Representatives, when in December 1998 it took up the question of President's Clinton's proposed impeachment. The hearings were a striking manifestation of the phenomenon addressed by Deborah Tannen in her recent book, The Argument Culture:

Our determination to pursue truth by setting up a fight between two sides leads us to believe that every issue has two sides - no more, no less. If both sides are given a forum to confront each other, all the relevant information will emerge, and the best case will be made for each side. But opposition does not lead to truth when an issue is not composed of two opposing sides but is a crystal of many sides. Often the truth is in the complex middle, not the oversimplified extremes. (Tannen, 1998, p. 10)

In the case of the Judiciary Committee hearings, a matter of considerable complexity was forced into the polarized form associated with our government's partisan structure. For those of us following the televised proceedings, the phenomenon was frustrating: while we observed considerable eloquence in the impressive variety of ways our representatives could rehearse the same arguments, we saw nothing that could authentically be termed deliberation. There was no possibility, in that polarized structure, for participants to explore "the complex middle."

The issues leading to the Clinton impeachment fall into the category that Pearce and Littlejohn have labeled "moral conflict" in their 1997 book of that title. Such conflicts, according to Pearce and Littlejohn, are "vexing disputes that ordinary discourse will not resolve" (1997, p. 5). They elaborate on their view:

Bruce Hyde and Jeffery L. Bineham, Department of Speech Communication, St. Cloud State University. An earlierversion ofthis essay waspresented at the annual conference ofthe Speech Communication Association, San Antonio, 1995. Correspondence concerning this article should be addressed to Bruce Hyde, Department of Speech Communication, St. Cloud State University, 720 FourthAvenue South, St. Cloud, Minnesota, 56301 orbyelectronic mail to rbruce@ stcloudstate.edu. 
We have a deep appreciation for the arts of persuasion and debate. Our professional training led us to expect that . . . plain old-fashioned persuasion and debate would lead eventually to truth-or at least to communal judgment. We presumed that failures to reach a decision or settle a dispute were caused by unskilled communication, poor debate technique, or selfishness. Events . . . however, taught us that not all conflicts have resolutions and that the rhetorically eloquent presentation of one's case sometimes intensifies, rather than settles, the conflict. They taught us that the use of the best argumentation sometimes widens, rather than narrows, the breach. (p. 5)

Regarding the Judiciary Committee's hearings, party loyalty was certainly one factor shaping the debate. But unless one assumes that committee members had made a reasoned judgment to abandon their concern for the public good in the interest of partisan politics - and we are not willing to go so far as to make that assumption-one was struck by the dramatic failure of polarized discourse to deal effectively with moral conflict. Subsequent analyses of the situation by House members included complaints that the process had seemed to have "a life of its own," and had proceeded as if "it was on rails." The rails, we assert, were the two poles of the discourse, and their stubborn inflexibility kept the conversation on an unfortunate track. This provided a clear instance of "the chasm between deeply held views of the true and the good, which, when they come to clash, frustrate and anger both participants and observers" (Pearce \& Littlejohn, 1997, p. 10).

Educators in the field of speech communication are, as it were, the keepers of the culture's public discourse. We train our nation's future citizens and leaders in the art of deliberation, teaching them forms for talking about social issues. But, wedded as we are to the tradition of persuasion and debate, how effectively are we preparing them to address the vexing moral conflicts that persist in our public conversations (e.g., abortion, assisted suicide, affirmative action, gay and lesbian rights)? How well-suited is the familiar bipolar model in a culture whose increasing diversity has dramatically increased the number of voices and perspectives that demand to be heard?

Our concern with these questions has generated the project that this essay describes: a classroom exploration into the nature of public discourse, and into the possibility of teaching dialogue as a complement to argumentation, persuasion, and debate. The authors have undertaken a pedagogy of dialogue in several classroom contexts. Together, we have designed and taught an undergraduate course whose focus is the distinction between dialogue and debate as forms of public discourse. In addition, one of the authors has for several years taught an Honors course in dialogue, as well as a listening course based in John Stewart's dialogic listening model (Stewart, 1983; Stewart \& Thomas, 1989). In this essay, our purpose is to provide the rationale and some of the elements of our approach, so that others in the field may be inspired to create their own classroom inquiries into the possibility of nonpolarized public discourse. We feel strongly that this is an idea whose time has come, and that members of our discipline are the appropriate leaders of a movement to transform the way our culture talks about its problematic social issues.

In what follows, we first examine the way argument has come to be viewed in our culture and our discipline. Next, we explore the question of dialogue's teachability, and propose several central elements for a pedagogy of dialogue. Finally, we outline our design for a debate/dialogue course.

\section{FROM ARGUMENT TO DEBATE}

For purposes of this essay, the terms discourse and conversation refer to the genus of which debate and dialogue are species. Further, as we use the term, argument is a specific 
discursive element-a claim supported by evidence-which may appropriately be employed in either debate or dialogue. Daniel O'Keefe's differentiation between argument $_{1}$ and argument $_{2}$ (1982) is useful for the point we are making here. O'Keefe defines $\operatorname{argument}_{1}$ as "a kind of utterance or a sort of communicative act" (p. 121), the sort of act referred to in the statement "she made an argument." Argument ${ }_{2}$, on the other hand, is "a particular kind of interaction” (p. 121), the kind we mean when we say "they had an argument." The problems we observe in our culture's public discourse may be seen as a general devolution of argument ${ }_{1}$ to argument $_{2}$. The tradition has presumed that arguments $_{1}$ are most effectively structured as a debate, in which propositions are stated and defended against arguments $_{1}$ from an opposing position. But Tannen (1998) provides extensive examples of ways in which this presumption, and our well-meaning cultural imprimatur that there are two sides to every issue, have led us to increasingly inappropriate and contentious polarization.

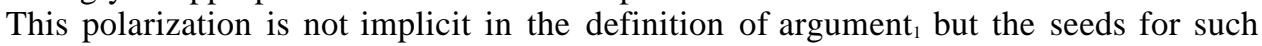
an interpretation may be found there. Wayne Brockriede (1975) defined argument as "a process whereby people reason their way from one set of problematic ideas to the choice of another" (p. 180). In practice, this typically means that argument involves two sets of problematic ideas, and that these possible resolutions are preexisting choices. Although arguers might construct a previously unconceived perspective, the traditional paradigm does not encourage this. It does encourage that the number of preexisting choices be reduced as far as possible, preferably to two, and that through a competition of reasons one will emerge as the more acceptable. Christopher Lyle Johnstone's 1995 essay in this journal, on the subject of ethics and political communication, illustrates the way this view plays itself out in the political arena. Ethical communication in democratic politics, he writes, must abide by the "rule of confrontation," which states that "only when ideas are subjected to . . . the 'dialectic of debate' - in which 'there is immediate challenge, reply, cross-examination, and rebuttal'-can they be tested and can those that are worthy of belief be distinguished from those that are not” (p. 98).

Another aspect of traditional argument that has shaped and limited its focus is its demand for the provision of reasons as support for ideas, or claims. In one sense, any expression of belief or knowledge is an argumentative claim that requires evidence or reasons for support (Crable, 1982). But argument as traditionally conceived in our society features a particular kind of reason-giving. Neil Postman (1985), describing this traditional ideal, states that argument relies on "propositional content," on a "coherent, orderly arrangement of facts and ideas," and on "a sophisticated ability to think conceptually, deductively, and sequentially; a high valuation of reason and order; an abhorrence of contradiction; [and] a large capacity for detachment and objectivity" (pp. 49, $51,63)$. One result of this ideal is our propensity to describe arguments formally as induction or deduction, both of which require that propositions be organized according to an appropriate and specific structure (the most obvious example being the syllogism). Although communication scholars are generally less interested in formal logic than philosophers, most of our argumentation texts do encourage an awareness of formal argument, so that debaters can attack faulty logic when they encounter it.

Our purpose here is not to deprecate this tradition. We recognize the value of logical argument, and we honor its practice. But the traditional emphasis on such reasoning has led to the rejection of other kinds of reasons as fallacious or anecdotal. Nowhere in formal academic debate, for example, is there a legitimate place for the consideration of personal experience, despite the importance of such experience in shaping our daily actions and decisions. And what about those situations-we believe the Clinton judiciary hearings were an example-when two worldviews collide? In such cases, say Pearce and Littlejohn, both groups have "rich ways of describing their own worldviews and [follow] strict codes of reasoning and argument," thus producing highly effective intramural discourse; but their incommensurate views produce inter- 
mural discourse that is little more than "reciprocated diatribe" (pp. 12, 13). As our culture becomes more diverse, such situations will inevitably become more frequent; and our tradition of argument, invaluable when appropriate, is bound to falter when confronted increasingly with issues whose incoherence and inherent contradictions perplex its formal standards.

Although argument tends toward a strictly logical and bipolar form, that is not its only possible direction. Henry Johnstone's view of argument (1965), for example, highlights characteristics that are not typically considered and that strongly suggest a more dialogic form of discourse. For Johnstone, argument is characterized by "open-mindedness and tolerance” (p. 7), and here he parts from the traditional conception that an arguer's goal is to produce reasons that cannot be refuted by counter-reasons. This would be the goal if argument were a means of control over others, but Johnstone emphatically rejects this notion. Any reasons, he asserts, could be refuted by counter-reasons, so argument cannot usefully be conceived as a set of strategies for manipulating others to a prescribed conclusion. The goal of argument, instead, is to facilitate open-mindedness and tolerance. This goal is best achieved, according to Johnstone, when one maintains a delicate balance: holding a "fervent commitment to [one's] own arguments" and at the same time recognizing that "all of them can be met by counterargument" (pp. 7-8).

Second, as conceived by Johnstone, the risk inherent in argument arises from the fact that participants may have to change themselves. This is because argument is not simply the transmission of reasons by "minds that already exist and already inhabit the world" (p. 7). Instead, argument is "constitutive of those who participate in it" (p. 6). For Johnstone, argument becomes a means of constituting self and world, rather than the strategic manipulation of symbols to support a preconceived end. This perspective does not denigrate the reason-giving function of argument. Indeed, reason-giving is seen as a constitutive activity, in which the creation of self and world depend upon the kinds of claims, data, warrants, and good reasons traditionally employed by the staunchest of academic debaters. Nothing prohibits the integration of these traditional argumentative forms, practiced with the sense of open-mindedness Johnstone encourages, into dialogue.

In summary, we propose that the problems that we observe in our public discourse are not caused by reliance upon argument,, but by the strongly oppositional contexts in which we argue. The roots of this oppositional trend may, as we have shown, be traced to definitional aspects of argument, which have over time been elaborated and encouraged. But our interest as communication educators is to explore, with our students, other discursive ways to deal with issues-forms of conversation in which ideas may be collaboratively nurtured and developed, rather than challenged or rebutted.

\section{CAN DIALOGUE BE TAUGHT?}

Although speech communication departments in this country regularly offer courses in persuasion and argumentation, courses in dialogue are rare. This is not surprising. Dialogue, as a discourse form, is characterized by a commitment to openness and indeterminacy, making precise formulation or pedagogical explication problematic. Further, practitioners and theorists of dialogue often differ widely on their definitions of the term. Cissna and Anderson, in the first chapter of their 1994 volume The Reach ofDialogue (edited with Arnett), have traced the traditions of dialogue presented in the works of Buber, Bakhtin, Gadamer and others. Dialogue in these traditions is variously conceptualized as a type of relationship, a form of communication, a framework for knowledge creation, an interaction between interpreter and text, or a characteristic of language itself (Cissna \& Anderson, 1994, pp. 10-13). Particularly in the work of Buber, whom Stewart has called "the one author who initially did the most to describe dialogue and attempt to place it at the center of the human studies" (1994, p. ix), dialogue is ulti- 
mately seen as a way of being with another person. In current popular usage, on the other hand-includingfor example, President Clinton's recent call for a "national dialogue on race"-what is being referred to is clearly a way of talking with others.

Therefore, in considering the possibility of a pedagogy of dialogue, the first step is to specify just what it is that we mean to teach. To clarify this task, we will borrow from O'Keefe the idea of subscript use, so that we may differentiate between two phenomena which we will refer to as dialogue ${ }_{1}$ and dialogue ${ }_{2}$.

Dialogue $_{1}$ indicates a fom of discourse. Specifically, dialogue ${ }_{1}$ is non-polarized discourse. Its dynamic is not oppositional, but collaborative. Its proposed outcome is not the ascendance of one perspective over another, but the fusion of all perspectives to enable a larger, more inclusive view, one which allows the tension of disagreement. From within this common understanding, resolutions may be created that could not have been foreseen from any partial view. Participants in dialogue ${ }_{1}$ may make arguments - thais, they may make claims and support these claims with reasons-but in a dialogic context these claims are included rather than rebutted, and are explored for areas of commonality rather than points of clash. Rigorously collaborative, dialogue ${ }_{1}$ is the potential wellspring of what Bohm calls "social intelligence" (Zimmerman \& Coyle, 1991). Such conversation generates new possibilities in communities and organizations by fostering collective thinking.

Dialogue $_{2}$ is a relational space. This is the ontological aspect of dialogue, the dialogic way of being with another person. It is referred to variously by Buber $(1987,1988)$ as the between, the interhuman, and the I-Thou. Dialogue ${ }_{2}$ is a manifestation of that state of ontological human relatedness that Martin Heidegger calls Being-with (1962, pp. 153157). It is characterized by openness, trust, presence, and an understanding of the other that arises not from psychological compatibility but from shared humanity. As Cissna and Anderson (1998) have suggested, this way of being may manifest as "an extended state of high quality mutuality," or it may consist of "dialogic moments" "important yet ephemeral moments of human meeting" (p. 63). Dialogue ${ }_{2}$, however fleeting, is ultimately the heart of dialogue.

With regard to a pedagogy of dialogue, our experience is that a speech communication class can reliably and consistently provide students with an important experience of dialogue $e_{1}$ an experience that will reveal to them both the limitations that polarized discourse imposes upon our ability to deal effectively with problematic social issues, and the possibilities that dialogue affords for addressing such issues. In our view, dialogue is a much-needed practice in our culture, and the development of a pedagogy which can produce it is a highly appropriate and attainable goal for our discipline. Dialogue ${ }_{1}$ can be taught, and we-speech communication educators-are the people to do it.

Dialogue $_{2}$, on the other hand, is elusive. According to Buber, it comes by grace (1987, p. 11). It is not subject to pedagogical formalization, and cannot be promised in a course syllabus. Therefore we emphasize that the insights of dialogue ${ }_{1}$ may be attained fully, whether or not they are accompanied by an experience of dialogue ${ }_{2}$. We cannot guarantee our students an I-Thou relationship with their classmates; but we can show them how to avoid the frustrations of polarized argument, and thus we can begin the important work of transforming our culture's public discourse.

At the same time, we must note that the relationship between dialogue ${ }_{1}$ and dialogue $_{2}$ is a subtle one. The practice of new forms of discourse will inevitably affect our natures as communicative beings. Thus the practice of dialogic communication often generates transformative experiences of dialogic relatedness and mutuality. Students in our classes frequently remark on the sense of authentic relatedness that characterizes their dialogue sessions. They begin by learning how to engage in a nonpolarized conversation, but may end by being more open and trusting with each other. Thus, although the goal in our classes is primarily a pragmatic pedagogy of dialogue as a discourse form, as educators we remain always open to moments of 
dialogue, and invite them whenever and however we can. Their possibility makes a dialogue classroom a potentially extraordinary educational environment.

\section{ELEMENTS OF A PEDAGOGY OF DIALOGUE}

Unlike debate, the essential particulars of dialogue cannot be formalized. The pedagogical approach that we have taken, therefore, is to distinguish dialogue as a possibility in discourse. This approach draws on the work of Landmark Education, an organization whose educational methodology has been the subject of considerable research by Hyde (1990, 1992, 1994, 1995). Landmark's pedagogy is based in the dialogic development of distinctions. According to Steve Zaffron of Landmark

Getting a distinction is like what happens as you learn to ski. When you first stand at the top of a slope and look down all you see is a lot of snow and a really steep drop-off. As you practice and become more expert, you begin to be able to see differences between one slope and another. Standing at the top of a slope you see moguls and other subtle variations in the terrain that make for easier or more difficult paths down the mountain. In addition, the mountain no longer seems so steep. These characteristics of the mountain were always there, but before you just didn't see them. That's what getting a distinction does. (Wruck \& Eastley, 1997, p. 8)

From this perspective, it can be said that the possibility of dialogue exists in many conversational encounters, but has not been distinguished for most of us. Our cultural predisposition is to listen for opportunities to agree or disagree, not to engage in dialogue.

In Zaffron's example above, practice in skiing is a process of developing distinctions. Coursework in dialogue has the same purpose. The goal is not to learn concepts, but to distinguish the possibility of dialogue in interaction. For the trained skier, a trip down the mountain does not involve applying information that he or she has learned. Rather, the training has altered the world of the skier so that the mountain occurs as skiable. Coursework in dialogue is likewise designed to alter the participant's world so that conversations occur naturally as openings for dialogue.

Distinctions differ from concepts. One understands concepts, but one dwells in distinctions; they transform one's reality. For example, conditions for much of humanity have been transformed by the introduction into the world, at some point in history, of human rights. This transformation has occurred, not because we understand the concept of human rights, but because we dwell in the distinction. For most of us, our world is such that human beings simply occur for us as beings with rights, and we respond appropriately.

Distinctions also differ from definitions. Definitions provide limits; distinctions generate possibilities. For example, at one point during his term as U.S. president, Jimmy Carter convened a World Conference on the Family. It drew an international body of participants, all of whom had demonstrated in their countries a commitment to family issues. But the conference failed to accomplish its first order of business, which was to agree on a definition of "family." This failure is not entirely surprising; within our own culture, we struggle as new forms of family-single-parent, extended, gay/lesbiancontend for inclusion within our model. "Family" is not, at this point, easily defined. But participants at Carter's conference, despite their cultural differences, had certainly distinguished family; their backgrounds demonstrated active commitment to the possibility indicated by that term. They did not, however, recognize the difference between distinction and definition. Therefore they remained stuck in a struggle at the level of definition. Rather than exploring the range of definitions that could be generatedfrom the distinction "family," they felt constrained to seek a specific definition of "family." This focus made salient their differences rather than their mutual understanding. 
Consider another example: art as a distinction. From early in life, we begin to receive hints about the nature of art. Generally our first conceptualization of art, learned in elementary school, is drawing and painting. Later we learn that sculpture, music, and literature may be art, and that there are also performing arts and even culinary arts. Over the years, we read and think about art, and stand or sit in the presence of many works of art. As a result of these experiences, we may begin to distinguish art as a realm, a way of seeing, a clearing in which to encounter a painting or a performance; and sometimes, the possibility having been distinguished, these things may occur for us as art.

The process of developing a distinction, then, is not necessarily linear or logical. It is, rather, a matter of engaging in a number of related conversations and activities that, collectively, unconceal the new possibility. Based upon our experience, we believe that there are several topics whose discussion is useful, if not essential, in order to distinguish dialogue. In the next section of this essay, we briefly explore three of these topics: language, identity, and presence. This exploration is intended to suggest ways of developing a pedagogical conversation that will engage students actively in creating the possibility of dialogic communication.

\section{Language as Constitutive of the World}

To those in the discipline of speech communication, the notion that language is not merely representational, but provides the world with its meaning, is not a new one (see, for example, Bineham, 1995; Brummett, 1976; Deetz, 1973; Scott, 1967; Stewart, 1995). But we suggest that while many of us understand this theory, far fewer of us live it. In large part, most human beings are commonsense Cartesians. We spend much of our lives struggling with the way things "are," rather than savoring the malleability that a constitutive view of language, fully distinguished, might lend our world. The aim of a classroom conversation on this topic, then, is that students begin to dwell in the possibility of such a view, and not merely understand the theory. To gain access to the generative nature of dialogue, one must be open to the power of language to create meanings.

In our experience, one of the most difficult points for students to grasp here is that "language" does not refer merely to words, but to the understanding of things that accompanies the words. For those in our society, for example, the word "chair" calls forth an understanding of the nature and function of chairs. In other cultures, other words (e.g., chaise) evoke a similar understanding. But imagine a culture where there were no chairs - aulture where people stood, or sat on the ground, and whose language, and corresponding understanding of the world, did not include chairs. If someone from such a culture encountered an object of the kind that we know as a chair, that object would not occur for him or her as a chair. Thus chair-ness is not implicit in the object. Beinga-chair arises in language. Nor is language limited to words; to sit in the object is to language it as a chair. In the words of Einstein, "It seems that the human mind has first to construct forms independently before we can find them in things" (1954/1982, p. 266).

A useful example of the role of language in creating the world is found in Helen Keller's autobiographical accounts of her early childhood $(1908,1955)$. Stricken at nineteen months by an illness which left her unable to see or hear, Keller was virtually without language and the understanding it makes possible. Writing of that period, she refers to herself as "Phantom," a "little being governed only by animal impulses. . . . . Her few words wilted [and] silence swooped upon her mind and lay over all the space she traversed (1955, pp. 37, 41). Thus Keller was not merely wordless, she was worldless. "Before my teacher came to me," she writes, "I did not know that I am. I lived in a world that was noworld (1908, p. 113). But when she was awakened by her teacher to the meaning-function of language, "the nothingness vanished (1955, p. 42), and Keller was awakened simultaneously to both a self and a world: "When I learned the meaning of 'I' and 'me,' and found that I was something, I began to think. Then consciousness first existed for 
me” (1908, p. 117). Keller's story is a useful pedagogical tool because it demands that students consider the question: what would it be like to exist in a world of objects but no meanings? Struggling with this question-as they must, immersed as they are in an environment of meaning - they confront the role of language in creating their world.

To this end, it is likewise useful to contrast the linguistic world of human beings with the environment in which other animals exist. As Freire (1993) points out in his discussion of language and dialogue, human beings are the only beings who think about themselves and their actions. Other animals "are unable to separate themselves from their activity and thus are unable to reflect upon it" (p. 78). Thus we suggest to students that they eliminate the cartoon thought-balloon that they are accustomed to seeing above the head of Garfield and Snoopy, and imagining above the heads of their own pets. Nonhuman animals, says Freire, cannot set objectives, or commit themselves, or take risks, since all of these involve meaningful reflection. Nor do animals "have" emotions in the same way that human beings do; it is more accurate to say that animals are their feelings. Freire borrows Sartre's terminology to designate this difference: animals are "beings in themselves," whereas humans are "beings for themselves" (pp. 78-81). An example from Schudson (1997) is relevant: "Charles Darwin argued that every human expression of emotion except one has an analogue in other species. The distinctively human manifestation of emotion is blushing; Darwin explains that it is 'the thinking what others think of us that makes us blush"' (p. 302). Only humans, as beings for themselves, experience the reflexivity that gives rise to a blush.

These are challenging ideas for students to contemplate, especially because any understanding of the "inner lives" of nonhuman animals is, to some degree, speculative. But the empirical unresolvability of the matter is not an impediment to its pedagogical effectiveness. Ultimately, the point of this conversation is not to argue whether or not animals think, but to provoke students' active engagement with the question of language.

Thus, for pedagogical purposes, it is useful to state the matter provocatively. For example: Napoleon did not have an ego; the ego was invented by Freud, and wasn't available during Napoleon's lifetime. This idea violates students' common sense. Surely, they argue, the ego was always there. Freud simply discovered it and named it. But there is no ego. Ego, as well as the rest of the Freudian vocabulary, was created by Freud as a way of explaining his observations of human behavior. Subsequently, when human actions were observed through the lens of Freud's psychological distinctions, we were provided with a new understanding of our behavior, and consequently a new way of understanding, and being, ourselves. We are not simply pre-Freudians with new labels. Since Freud, we have dwelt in a transformed self-understanding; and this is not because Freud "discovered something "true" about human beings (many of Freud's ideas are, of course, being challenged by contemporary theorists), but because he created a new language. This creative process was not arbitrary; Freud did not simply "make things up." His vocabulary fit what we saw, and illuminated it. As a result, members of our culture have for years been matter-of-fact Freudians, assuming unthinkingly that the ego is as solid a piece of the human equipment as the head or the hands, and that it always has been.

A final idea to provoke student thinking about language: Newton invented gravity; prim to Newton, gravity did not exist in the world. Students, of course, protest this statement vehemently; but they can be led at that point to consider that Newton did not merely label or explain an already existing phenomenon. Certainly there was, before Newton, a physical force; but Newton transformed the possibility of that force. Here is Heidegger's challenging statement regarding the nature of Newton's thought:

Before Newton's laws were discovered, they were not "true"; it does not follow that they were false. . . .Just as little does this "restriction" imply that the Beingtrue of "truths" has in any way been diminished. To say that before Newton his laws were neither true nor false, cannot signify that before him there were no 
such entities as have been uncovered and pointed out by these laws. Through Newton the laws became true and with them, entities became accessible in themselves to [human beings]. Once entities have been uncovered, they show themselves precisely as entities which beforehand already were. Such uncovering is the kind of being which belongs to "truth.” (1962, p. 269)

Thus, just as Freud observed human behavior, Newton observed the physical universe; and just as Freud invented a vocabulary that made phenomena accessible in a new way, transforming our understanding of ourselves, so Newton invented a new way of understanding the universe. In doing so, he expanded our world. This is the central point: a Newtonian universe is not simply the old universe with new labels. The possibilities for existence have been transformed by the new truths brought forth by the new language.

Human beings can inhabit only the world that has been distinguished in language by human thinking. The languaged world is, for human beings, the real world. Thus, one thousand years ago, the earth was flat. We recognize now the limits of that understanding-just as our late-twentieth-century understanding will undoubtedly seem limited to those living millennia hence. But as Stewart has pointed out, human beings do not live in "ontological outer space" (1995, p. 108). We inhabit the world given by human understanding in our time, and a thousand years ago, humans were given a flat surface. The earth became round when human thinking distinguished that possibility. And even that understanding of things may not be the "truth" of the matter, since physics continues to create new ways of seeing. Einstein's statement on this point is a clear and eloquent pedagogical tool:

Physical concepts are free creations of the human mind, and are not, however it may seem, uniquely determined by the external world. In our endeavor to understand reality, we are somewhat like a man trying to understand the mechanism of a closed watch. He sees the face and the moving hands, even hears its ticking, but he has no way of opening the case. If he is ingenious, he may form some picture of a mechanism which could be responsible for all the things he observes, but he will never be quite sure his picture is the only one which could explain his observations. He will never be able to compare his pictures with the real mechanism, and he cannot even imagine the possibility or the meaning of such a comparison. (Einstein \& Infeld, 1938, p. 33)

\section{Identity}

Perhaps the single greatest barrier to dialogue is the pervasive human impulse to defend one's identity - one's self; and whatever one identifies with and as oneself-from any perceived threat. When dialogue breaks down, it is invariably due to someone's holding tightly to the rightness of some position with which they identify themselves. Must we then suggest that participants in dialogue give up their values and beliefs in the interest of collaboration, and surrender their right to take a stand? Emphatically not. Instead, we find it valuable to differentiate between being right and being committed. Being right about one's position on an issue makes other positions wrong; being committed to an authentic inquiry, on the other hand, gives room to engage productively with other points of view. Being right is a function of personal identity and its survival. Dialogue is the possibility of a commitment to something larger than one's identity.

Recent inquiry into the source and nature of human identity has begun to "decenter" the human subject, the carrier of personal identity, from its traditional role as the arbiter of human action. We suggest that if the full possibility of dialogue is to be realized, students must be introduced into this decentering process, so that aspects of their identities-beliefs, values, assumptions - can be subjected to authentic questioning. Generating this decentering conversation is, perhaps, the ultimate challenge for a 
pedagogy of dialogue, in part because we live in a culture where, on all fronts, people are being encouraged to build stronger identities-personal, ethnic, cultural, and subcultural. Self-esteem, we are told, depends upon a robust identity. Yet, at the same time, the culture and the world grow increasingly fragmented and contentious at the boundaries of these stronger and ever more numerous identities.

But if dialogue is to be reached, the question must be raised: what is the origin and function of identity? What is a "self," anyway? For the most part, unthinkingly, students assume that the personal pronoun "I" indicates a substantial entity of some kind that inhabits their body. It is vital, then, for them to consider that their body arrived on the scene before the "I" did, and that the "I" is, for the most part, their own creation. A human infant has no "I"-it has little or no sense of self, and no self-reflexive awareness (Dinkmeyer, 1965, p. 188; Stern, 1985, p. 6). But as the infant's inborn capacity for language and self-reflection begin to awaken, and she or he notices a perceiver at the center of the perceptions, the infant begins creating an identity for that perceiver, primarily in response to early interactions with significant others. Thus, as one's world begins to have meaning, one designs an identity that is harmonic with the meanings of that world, and appropriate for living and surviving in such a world.

A "self," then, may be seen fundamentally as a conversation. If you ask a student to tell you about him or herself, he or she will respond with a list of values, beliefs, goals, interests, and historical events. Generally, we might say that this is a conversation about the self. But it may be more accurate to say that this conversation constitutes the selfthat a self is a nexus of meanings surrounding a site of agency and perception, meanings that each of us aggregates over the years in response to the situations and interactions we encounter as we live.

Further, the thrust of identity, once it exists, is to perpetuate itself: The situation is stated here in Heidegger's treatise on the thinking of Nietzsche:

That beings are-the "condition of preservation" for life-need not be thought in such a way that beings are something constant, existing in and for themselves "above" and beyond life. The only condition is that life instill of itself and in itself a belief in something it can constantly hold onto in all matters. . . . To be able to be as life, life needs the constant fixity of a "belief," but this "belief" calls for holding something to be constant and fixed, taking something as "in being." (Heidegger, 1961/1991, p. 62)

What one holds onto, as the vehicle for existence, is personal identity-including those elements of other identities (ethnic, national, etc.) that one has incorporated into one's self. If "I" cease to exist, existence as I know it ceases; and we are not making the obvious biological point here, but the ontological one. For a self-reflective being, continuing existence is accomplished by maintaining the validity of those meanings that constitute one's self.

Thus, our actions are driven largely by the survival needs of an invented identity, a drive cloaked in meaning and significance, in the cause of which we inflict massive suffering upon ourselves and others. This is not to say that we do not, in the process, experience love and joy. But the context for these experiences, and the cause they ultimately serve, is identity. To sacrifice for others-to trade material rewards for the satisfactions of "selflessness"-is a move to a subtler level of personal gratification. Although such sacrifice may greatly benefit others, self-interest is unavoidably imbedded in all our actions, even our best ones. Further, to deny that this is so is to validate it, because such denial is itself an act of self-interest.

Why is this point important? Why is it valuable for students of dialogue to contemplate their inescapable self-concern? Because it allows the realization that human defensiveness - the need to be right, the tendency to defend one's position rather than open it to inquiry-is not a psychological phenomenon, but an ontological one. Defensiveness is not the closed-minded impulse of an individual personality. It is a manifesta- 
tion of the nature of being; it is being doing its thing, that is, continuing-to-be. Therefore, in the interest of distinguishing the possibility of dialogue, the goal of an inquiry into human identity is to create the possibility that participants may give up taking their own defensiveness personally. If one can recognize defensiveness as an inevitable aspect of human being, and can grant it being without feeling personally to blame for it, there is a possibility beyond it. This is the beginning of responsibility as a freedom, and a transformed relationship to identity. Heidegger proposed that an authentic self is one that has broken through its concealments and disguises, and has been "taken hold of" (1962, p. 167). If one can thus take hold of one's antidialogic tendencies-neither indulge nor resist them, but own them, allow them, suspend them, observe them-one is no longer owned by them. One is then nearer to an authentic embrace of one's own humanity, and an authentic acceptance of the humanity of others.

Inquiry into the nature of identity is important in distinguishing dialogue because, ultimately, the central question for a participant in dialogue is this: can I identify with the whole of the conversation, rather than my piece ofit? Can I stand in a commitment to a larger possibility than my own position? Am I willing to consider giving up a part of who $I$ am, in the interest of what we might become? Such willingness is more likely if one recognizes the constructedness of one's identity.

One of the most important results that we have observed in our work with dialogue is a particular shift in students' relation to their position on an issue. This shift is away from "I hold this view because it is the right position," and toward "I hold this view because of my background and experiences; my position on this issue is the natural result of those experiences." More importantly, this shift is accompanied by a corresponding move from "The person who holds an opposing view to my own is wrong," toward "This person's opposing view is a natural result of their background and experiences, and I understand why they hold that view." We believe that this is the essential first step in achieving dialogue. It does not mean that, at this point, the student changes his or her opinion, but that she or he has reached the point of respectful understanding of the other's perspective. This is the point from which authentic dialogue can begin. This shift is achieved, we believe, by distinguishing the constructed nature of human identity.

\section{Presence}

Finally, an idea that is central to dialogue as we understand it is the notion of presence or presentness to the other. Here again, the conversation is challenging, because the terrain is tricky and rich with paradox. Any definition or conceptualization of presence cannot capture the phenomenon, because, if one is engaged with a concept of presence, one is not present. To be present is to be in the world at the moment, not "in one's head." So the challenge for a pedagogy of dialogue is to design an inquiry whose aim is not to define or explain presence, but to create the possibility of actually being present.

Buber's work, especially the opening sections of I and Thou (1958/1987), are particularly useful for generating this discussion. For the most part, according to Buber, we relate to the world through the filter of the past (an I-It relationship). Who we know ourselves to be, and what we know about others, are products of the past. I know who you are because I know who you were; but this situation leads to objectification. In a state of pure presence, I would see you newly in each moment, unlimited by the strictures of my past experience. Such a state, however, is unimaginable, and would be untenable. In its pure form, a perpetual condition of presence would have us wondering each morning who the person in the mirror is, would rob us of the often valuable opportunity to learn from our experiences, and would leave us boggled in our attempts to navigate everyday existence. Therefore, as Buber makes eloquently clear, all presence must quickly devolve into past. Moments of presence, as soon as they are noticed, become memories or concepts of presence. 
But it is valuable to think hard about what is meant here by a "moment." When we speak of a "moment of presence," we are not talking about an instantaneous point in clock-time. "The present is not fugitive and transient," says Buber, "but continually present and enduring” (1958/1987, p. 13). It is as if, when one is present, one is standing outside of clock-time. Presence expands time. In moments of presence, one senses that time may not be the rigid grid of seconds, minutes, and hours within whose confines we ordinarily exist. All of us have experienced such moments, when we were surprised during an event to discover, glancing at a clock, how much (or how little) time had passed. Our commonsense objectivist tendency in such moments is to credit clock time as valid, and to discount our own experience of lived time as a psychological aberration. But perhaps not. An inquiry into the possibility of time as a malleable phenomenon may be useful in distinguishing a dialogic way of being.

Presence is elusive, but it may be glimpsed, and moments of presence can be achieved. Although fleeting, such moments may prove transformative. The problems that prevent dialogue-all the personal, social, and cultural identity issues that divide us-are artifacts of the past. Racism is not present. In a moment of pure, naked presence, there are only you and I as possibilities, and the possibility of the human relationship, a blank canvas upon which to create. An inquiry into presence is an important aspect of preparation for dialogue.

\section{DEBATE AND DIALOGUE: A COURSE DESIGN}

Because classes in argumentation and advocacy are common in speech communication curricula, we believe that an effective way to introduce coursework in dialogue is as an element of these classes. So far, we have explored the possible theoretical components of such a course. In this final section, we outline the activity structure of the course that we have taught, a course specifically designed to have students think creatively about the possibilities of dialogic public discourse on controversial social issues.

Debates

We begin the course with two weeks of substantial lecture and discussion of reasoning, logic, and argument structure. Following this, we undertake the first activity by asking students to indicate, on a two-page questionnaire, their positions on certain controversial social issues (abortion, gay/lesbian marriage, etc.) as well as how strongly they feel about their positions. The information we obtain enables us to divide the class into two-person like-minded debate teams, and to schedule teams to debate before an audience a subject about which they feel, and disagree, strongly. The debates are organized to allow each team time to explain their positions, ask questions of the other team, rebut the other team's contentions, and conclude. Although we emphasize to students that the goal of the debates is not to "win," but to help the audience make an informed decision on the issue, the debates invariably take on a highly polarized, win-lose dynamic. Therefore, by the time the entire class has engaged in their debates, students begin to see clearly how this form of communication encourages participants to embrace one position as the "right" one and to defend it unflinchingly. Many remark that although they discovered points upon which they agreed with their opponents, they felt frustration that the debate format did not allow them to acknowledge and explore these commonalities.

\section{Dialogue groups}

Following the debates, we engage students in several weeks of extensive inquiry into the aspects of dialogue discussed earlier in this paper. We then place them in dialogue groups of eight people, and assign each group a controversial social issue. As with the 
public arguments, we arrange the groups so that each includes students with diverse and strongly held views on their topic. The groups are assigned to meet on their own and to engage in dialogue about their issue. The form of the dialogues is based upon the native American tradition of council, which employs a talking stick (Hyde, 1993). Each group chooses an object to regulate the conversation. The group sits in a circle and passes the object clockwise; only the person holding the object may speak. This ensures that no one is interrupted, and that all perspectives may be fully voiced. We have found this method to be extremely effective at breaking down polarization, and preventing the dialogue from becoming a contest of opposing views. Students who might normally dominate the conversation are forced to listen; students who do not generally participate actively are given an attentive hearing.

Positioned as they are immediately following the debates, the dialogue groups demonstrate clearly to students the possibility of a discourse that encourages the inclusion of multiple perspectives rather than a reduction to bipolar opposition. While students in the dialogue groups still make arguments and provide reasoning and evidence, these are not the exclusive criteria forjudgment. Personal experiences, anecdotes, and narratives, so important in shaping our real-life views, enjoy a legitimacy in the dialogue circles that they are not afforded in the debates. Finally, students find a freedom to explore their uncertainties and their areas of agreement, and to acknowledge their own "gray areas," rather than suppress them as detrimental to the black-and-white of debate. One student, whose group's topic was abortion, remarked that when the stick made its first round of the circle, each person was either pro-life or pro-choice. By the time the stick had made several more rounds, they found that there were as many different views on the topic as there were people in the group.

\section{Public conversations}

These dialogue groups are useful for relatively small numbers of people, rather than for discussions meant to involve the public at large. But as our concern in this course is to enhance public conversation about controversial issues, we want students to discover a form of talk that employs the positive aspects of argument and dialogue, and that might be appropriate to a public forum. To accomplish this, we once again divide the students into groups, and assign them to design a public conversation about one of the previously debated issues. The purpose of the exercise is for students to create a form for public discourse by drawing upon their understanding of argument and dialogue; the conversation they create should leave their audience better able to make a decision on the issue. We do not ask them to deny or ignore their own feelings or opinions on the topic, but we encourage them to explore questions in their discourse rather than defend positions. Each group then presents its product to the class. We encourage them to be creative, but we require that they be well-informed, and demonstrate that they have engaged in substantial research on their topic.

Groups in our classes have developed various approaches, some more successful than others. One group, for example, used the council form for one turn around the circle, then opened the discussion to the entire class (giving the "public" a direct voice), returning to the council form whenever audience participation slowed down. This structure enabled group members and audience members to explore the issue in a relatively nonthreatening and productive fashion. Whatever form they choose, students in this exercise are actively engaged in the creation of collaborative discourse, and are struggling productively against their culturally inherited tendency toward polarization.

\section{Final papers}

The value of these activities became especially clear as we read the final papers, in which students were asked to compare and contrast their debate and dialogue experi- 
ences, to examine the strengths and weaknesses of each, and to consider how both could inform a perspective that would encourage productive talk about difficult issues. Although many students wrote well about the theoretical aspects of the course, some of the most interesting insights came from their personal experiences. One student, for example, wrote of a group member who was "far less threatening in the dialogue group than in the previous [debate]. The dialogue format allowed him the freedom to move into the so-called gray area: thus he didn't have to defend [his position].” Another student, whose dialogue group discussed abortion, wrote, "I went into the group with basically just my opinion and my facts, not believing for a second that they could be changed. To my surprise, I came out of the group with more information and new questions and a lot less of an idea [about] where I stand on the topic. To me this was a very positive experience." This erosion of dogmatism, and the discovery in its place of openness, is a frequent result of these classroom experiences.

In sum, we were pleased that this course allowed students to think outside the bipolar boxes to which they were accustomed. We believe that this result is a vital one. Teacher-scholars in our discipline should continue to explore how best to create in students a sensitivity to, and a propensity for, dialogue. The course we have outlined here is but one method-a method that has worked for us - to teach some ideas and practices that are central to dialogue. Certainly other methods exist and still others will be created, and we hope that a continuing conversation about issues related to teaching dialogue will lead to both a deeper understanding of dialogue as a communicative form, and an increased ability to practice dialogue in our personal and public lives.

\section{EPILOGUE}

In a recent essay on conversation and democracy, Schudson writes that "democratic talk" is essentially civil, oriented to problem-solving, public, and, because it involves diverse people and ideas, uncomfortable (298-299). The view of dialogue to which we are committed is consistent with Schudson's perspective. We are not interested here in a dialogue that consists of homogeneous social discourse and thus does not feature the need to address tough public problems about which people hold conflicting views. Our most practical goal is to develop the practice of dialogue as a complement to argument, especially argument as conceived by Johnstone. Our culture needs (and wants!) a critical mass of people who will resist the simplicity of polarized debate and embrace the possibility of public dialogue. The communication discipline is positioned well to address this need, and we hope our colleagues will join us in an effort to improve the quality of public talk about important issues.

This work should also produce some important theoretical outcomes. One conviction that underlies our work, for example, is that we should seek to operationalize our theoretical ideas about language as a constitutive force in human affairs. These ideas about language have a history in the philosophy and theory of communication (a short view might trace this history to the "rhetoric as epistemic" literature, a long view would trace it at least to Plato and the Sophists), and we want to tap into that history in order to suggest some practical applications of those ideas. In this paper we have done this by developing a way to teach dialogue premised specifically upon the idea that language is constitutive, and upon ideas related to the construction of identity and presence. Our focus is to develop the theory and practice of dialogue; but to do that also requires development of these related concepts, and so we hope our essay advances theoretical discussions about the connections among communication, identity, and presence.

We also share a conviction that work of this type should encourage a scholarship of pedagogy. An earlier version of this essay was returned unreviewed by two journals in communication because, in one case, the journal did not publish articles about pedagogy, and, in the other case, the journal published only empirical studies of the effects 
of pedagogical strategies. These are legitimate editorial choices, but they made us aware of the constraints that inhibit sustained scholarly discourse on this and similar topics. So we hope that this essay provides an example of scholarship that integrates theoretical and pedagogical concerns. If we are to help create a culture of dialogue we certainly must confront both types of issues.

The challenge before us is daunting and worthwhile. It is daunting because our most basic cultural assumptions encourage us to engage in bipolar argument and to defend our positions against any challenge. But it is worthwhile because we live in a time of pluralism and difference when many people recognize the need for a more productive type of discourse. If we, as communication educator-scholars, can teach dialogue effectively, we can illumine one route to that more productive public discussion.

\section{REFERENCES}

Bineham, J. L. (1995). The hermeneutic medium. Philosophy and Rhetoric, 28, 1-16.

Brockriede, W. (1975). Where is argument? Journal of the American Forensic Association, 11, 179182

Brummett, B. (1976). Some implications of "process" or "intersubjectivity": Postmodern rhetoric. Philosophy andRhetoric, 9, 21-51.

Buber, M. (1958/1987). I and thou (R. G. Smith, Trans.). New York: Collier.

Buber, M. (1965/1988). Elements of the interhuman. In The knowledge of man (M. Friedman, Ed.; M. Friedman \& R. G. Smith, Trans., pp. 62-78). Atlantic Highlands, NJ: Humanities Press.

Cissna, K. N., \& Anderson, R. (1994). Communication and the ground of dialogue. In R. Anderson, K. N. Cissna, \& R. C. Arnett (Eds.), The reach ofdialogue: Confirmation, voice, and community (pp. 9-30). Cresskill, NJ: Hampton Press.

Cissna, K., \&Anderson, R. (1998). Theorizing about dialogic moments: The Buber-Rogers position and postmodern themes. Communication Theory, 8, 65104.

Crable, R. E. (1982). Knowledge as status: On argument and epistemology. Communication Monographs, 49, 249-262.

Deetz, S. (1973). Words without things: Toward a social phenomenology of language. Quarterly Journal of Speech, 59, 40-51.

Dinkmeyer, D. C. (1965). Child development: The emerging self. Englewood Cliffs, NJ: Prentice-Hall.

Einstein, A. (1954/1982). Ideas and opinions. New York: Crown.

Einstein, A,, \& Infeld, L. (1938). The evolution of physics. NewYork: Simon \& Schuster.

Freire, P. (1993). Pedagogyofthe oppressed. New York: Continuum.

Heidegger, M. (1962). Being and time (J. Macquarrie \& E. Robinson, Trans.). NewYork: Harper \& Row.

Heidegger, M. (1961/1991). Nietzsche III (D. F. Krell, Trans.). San Francisco: Harper-Collins.

Hyde, B. (1990). Saying the clearing: A Heideggerian analysis of the ontological rhetoric of Werner Erhard. Unpublished $\mathrm{Ph}$. D. dissertation, University of Southern California.

Hyde, B. (1992). Speaking being: Ontologicalrhetoric as transformational technology. Paper presented at the annual conference of the Speech Communication Association, Chicago.

Hyde, B. (1993, Winter). Using a talking stick to teach listening. Speech Communication Teacher, 7, 1-2

Hyde, B. (19943. Postmodern pedagogy: Speaking the unspoken. Paper presented at the annual conference of the Central States Communication Association, Oklahoma City.

Hyde, B. (1995). An ontological approach to education. Paper presented the annual conference of the Western States Communication Association, Portland.

Johnstone, C. L. (1995). Reagan, rhetoric, and the public philosophy: Ethics and politics in the 1984 campaign. Southern Communication Journal, 60,95108.

Johnstone, H. W. Jr. (1965). Some reflections on argumentation. In H. W. Johnstone Jr. \& M. Natanson (Eds.), Philosophy, rhetoric and argumentation (pp. 1-9). University Park, PA The Pennsylvania State UniversityPress.

Keller, H. (1908). The world I live in. NewYork Century.

Keller, H. (1955). Teacher: Ann Sullivan Macy. Garden City, NY: Doubleday.

O'Keefe, D. J. (1982). The concepts of argument and arguing. In J. R. Cox \& C. A. Willard (Eds.), Advances in argumentation theory and research (pp, 3-23). Carbondale: Southern Illinois University Press.

Pearce, B., \& Littlejohn, S. W. (1997). Moral conflict: When social worlds collide. Thousand Oaks, CA: Sage.

Postman, N. (1985). Amusing ourselves to death. New York Penguin Books.

Schudson, M. (1997). Why conversation is not the soul of democracy. Critical Studies in Mass Communication, 14, 297-309.

Scott, R. I.. (1967). On viewing rhetoric as epistemic. Central States Speech Journal, 18, 9-17.

Stern, D. N. (1985). The interpersonal world of the infant. NewYork Basic Books.

Stewart, J. (1983). Interpretive listening: An alternative to empathy. Communication Education, 32, 379391. 
Stewart, J. (1994). Foreword. In R. Anderson, K. N. Cissna, \& R. C. Arnett (Eds.), The reach of dialogue: Confirmation, voice, and community (pp. viii-xx). Cresskill NJ: Hampton Press.

Stewart, J. (1995). Language as articulate contact. Albany: State University of New York Press.

Stewart, J.. \& Thomas, M. (1989). Dialogic listening: Sculpting mutual meanings. In J. Stewart (Ed.), Bridges Not Walls (pp. 192-210). New York McCraw Hill.

Tannen, D. (1998). The argument culture: Moving from debate to dialogue. New York: Random House.

Wruck, K.H., \& Eastley, N. F. (1997). Landmark Education Corporation: Selling aparadigm shift. Harvard Business School Case Study 9-898-081, Rev. November 11, 1997. Boston: Harvard Business School Publishing.

Zimmerman, J., \& Coyle, V. (1991, March/April). Council: Reviving the art of listening. Utne Reader, 79-88. 